\title{
Normas como princípios de ação e capacidade reflexiva: fundamentos para a compreensão da Razão Prática kantiana
}

\author{
Norms as Principles of Action and Reflexive Capability: Foundations for the Comprehension \\ of Kantian Practical Reason
}

Paulo Henrique Rodrigues Pereira*

\begin{abstract}
REFERÊNCIA
PEREIRA, Paulo Henrique Rodrigues. Normas como princípios de ação e capacidade reflexiva: fundamentos para a compreensão da Razão Prática kantiana. Revista da Faculdade de Direito da UFRGS, Porto Alegre, n. 41, p. 70-90, dez. 2019. DOI: <https://doi.org/10.22456/0104-6594.84668>.
\end{abstract}

\section{RESUMO}

Críticos da teoria normativa legal têm discutido que essa linha de pensamento tem feito da racionalidade uma prática "causal", na qual a agência apenas refletiria uma espécie de sentimentalismo, sendo assim excluída das potencialidades da razão. Para esses críticos, a teoria normativa legal expulsou a contingência da ação do escopo da razão. Como resultado, fez indivíduos perderem a capacidade de deliberar, e a prática legal se tornou um exercício formalista, informado pela moralidade dedutiva. Este trabalho discute alguns desses críticos, argumentando que parte de suas oposições advém de uma má compreensão de como regras funcionam na realidade. Toma do pensamento de Christine Korsgaard e Onora O'Neill, dentre outros, que argumentaram que premissas falhas acerca da funcionalidade de regras são uma das fontes de tal desentendimento. O artigo aborda esse debate de uma perspectiva kantiana, referindo-se ao imperativo categórico e à Terceira Crítica de Kant como fontes úteis para analisar a teoria normativa legal. O Imperativo Categórico Kantiano foi atacado por muitos moralistas nos últimos dois séculos por ser excessivamente formalista, assim como como incompatível com a razão prática em sua formulação clássica. Este trabalho pretende questionar essa interpretação, argumentando que a visão kantiana de agência e deliberação não a apoiam se interpretadas com a devida consideração a aspectos de sua arquitetura moral.

\section{PALAVRAS-CHAVE}

Filosofia do Direito. Teoria Normativa Legal. Kant.

\begin{abstract}
Critics of normative legal theory have contended that this line of thought has turned rationality into a "causalist" practice, in which agency merely reflects sentimentality, being thus excluded from the potentialities of reason. For those critics, normative legal theory expelled the contingency of action from the scope of reason. As a result, the theory made individuals lose their capability to deliberate, and legal practice became a formalist exercise, informed by deductive morality. This paper discusses some of these critics, arguing that part of their contentions comes from a lack of understanding of how rules really work. It draws upon the thinking of Christine Korsgaard and Onora O'Neill, among others, who have argued that flawed premises on the functionality of rules is one of the sources of such misunderstanding. The article approaches this debate from a Kantian perspective, referring to the categorical imperative and to Kant's Third critique as useful resources to analyze normative legal theory. The Kantian categorical imperative has been attacked by many moralists in the last two centuries for being excessively formalist, as well as incompatible with practical reason in its classical formulation. This article intends to question this interpretation, arguing that Kant's views on agency and deliberation do not support this view if interpreted with due consideration to broader aspects of his moral architecture.
\end{abstract}

\footnotetext{
* Doutorando em Filosofia e Teoria Geral do Direito pela Faculdade de Direito da Universidade de São Paulo. Possui Graduação (2009) e Mestrado (2015) em Direito pela mesma Universidade. Tem desenvolvido pesquisa nas áreas relacionadas à Filosofia do Direito, Filosofia Moral e História dos discursos, com foco em relações entre Direito e Escravidão.
} 
KEYWORDS

Philosophy of Law. Normative legal theory. Kant.

\section{SUMÁRIO}

1. Introdução. 2. Apresentação do tema: as críticas à moral kantiana. 3. Regras como razão para agir. 4. O juízo e a capacidade reflexiva. 5. Conclusão. Referências. Dados da publicação.

\section{INTRODUÇÃO}

Os processos modernos de reflexão sobre o Direito e a Moral apresentaram elementos que se desenharam como centrais nas práticas sociais desses campos. Embora presentes na tradição clássica, alguma dessas características puderam ganhar contornos mais relevantes no pensamento moderno, ocupando funções e performances inéditas nas experiências jurídicas ocorridas sobretudo a partir do século XVIII. Uma série de pensadores foram fundamentais para o aprofundamento dessa tradição, em arranjos que na maioria das vezes se apresentaram no debate intelectual moral como combatentes da tradição prudencialista clássica, organizada em torno das noções da chamada Razão Prática, de viés aristotélico.

Muitos poderiam ser destacados como os elementos articuladores desse pensamento. Parece central, entretanto, a descrença na hipótese de uma razão de natureza prática, ideia pela qual se deslocariam as reflexões do campo da ação humana para uma perspectiva causalista, na qual a agência seria mero reflexo do sentimentalismo, como componente excluído das potencialidades da razão. Assim, homem e mundo, movidos por forças naturais e necessárias, se uniriam como objetos governados pela razão especulativa. A contingência da ação, expulsa do campo da racionalidade, perderia as suas potencialidades de disputa da reflexão moral.

A prática moderna, fortemente influenciada por essas noções, organizou um Direito formalista, de moral dedutiva, cujas capacidades de reflexão e deliberação, desprestigiadas, foram conceitualmente subestimadas.

Kant foi, sobretudo na sua recepção brasileira, apropriado por muitos como um dos representantes desse processo. A leitura da "Fundamentação da Metafísica dos Costumes e da Crítica da Razão Pura Prática” deu-se pela chave do formalismo, e do conceito de que sua teoria representava uma crítica às noções de agência e de prudência, como elementos formadores das capacidades morais humanas. Nessa interpretação, Kant tornou-se, ainda que indiretamente, um pensador contrário a uma perspectiva de razão prática.

Esse artigo pretende relativizar essa interpretação, dando indícios de que uma leitura melhor da obra kantiana necessita integrar a sua arquitetura moral a uma mais bem 
fundamentada perspectiva de agência e deliberação. Muitos poderiam ser os caminhos para esse percurso. Aqui, pretende-se traçá-lo por duas ideias simples, anotadas como ausências importantes na interpretação kantiana, sobretudo no Brasil. Esses eixos de argumentação analisarão a perspectiva da moralidade kantiana em dois caminhos: da norma para a ação, refletindo sobre como se processa a dedução das normas, e da ação à norma, na perspectiva de compreender o ato concreto de julgamento na busca por um universal apropriado.

Assim, a primeira delas relaciona-se com a interpretação acerca de como funcionam as regras, e de que tipo de reivindicação Kant pode ter feito na formulação do seu famoso imperativo. A segunda trata dos potenciais, para a compreensão do Direito e da Moral, presentes nas ideias kantianas acerca da capacidade reflexiva, ou reflexionante, como articuladora das relações entre os particulares e os universais. Aqui, será essencial uma breve leitura da terceira Crítica kantiana, a Crítica da Capacidade de Julgar.

O conceito central defendido, a rigor, é de que Kant não previu uma aplicação dedutiva do seu imperativo, como se esse representasse um motor causal, porque (i) as regras não funcionam dessa forma, e Kant sabia disso; e (ii) o pensador não pregou uma aplicação direta da lei moral, sem a intermediação de uma capacidade própria da racionalidade destacada para organizar essa transição. Essa é justamente a capacidade reflexiva.

Esse artigo, portanto, delineará, em primeiro lugar, (i) os argumentos centrais da crítica sofrida por Kant, na perspectiva desse trabalho; depois (ii) organizará reflexões sobre a noção de regras, na leitura específica do seu funcionamento como razão para a ação; e (iii) apontará questões relevantes sobre o que Kant disse sobre a capacidade de julgar. Por fim, (iv) serão trazidas as conclusões do trabalho.

\section{APRESENTAÇÃO DO TEMA: AS CRÍTICAS À MORAL KANTIANA}

Kant formulou uma moral com pretensões universais, gerais e abstratas, e na sua crítica às chamadas inclinações, a organizou a partir da noção de um imperativo categórico ${ }^{1}$. O imperativo deveria prover as respostas morais independente das situações concretas dos agentes, das suas condições especificas, e dos elementos informadores da ação. Se

\footnotetext{
${ }^{1}$ Kant deduz o imperativo da moral vigente à pressuposição da regra moral, na sua Fundamentação da Metafísica dos Costumes (KANT, Immanuel. Fundamentação da Metafísica dos Costumes. Trad. Guido Antonio de Almeida. São Paulo: Barcarolla, 2009). Na segunda crítica, a Crítica da Razão Prática, o autor demonstra a formação da lei moral, pela chave da liberdade como centro da sua causalidade (Id. Crítica da Razão Prática. Trad. Afonso Bertagnoli. Rio de Janeiro: Nova Fronteira, 2013.). Esse ponto será bastante importante para a formulação das ideias centrais desse artigo.
} 
apresentaria como uma resposta inatacável, surda às consequências e eventuais externalidades particularistas de sua aplicação. Preocupado naquele momento em contrapor o utilitarismo, Kant buscou uma fórmula moral independente de toda e qualquer experiência, advinda exclusivamente da razão ${ }^{2}$.

Muitos interpretaram tal movimento como uma adesão do campo moral à razão especulativa. Nessa perspectiva, haveria uma colonização das diretrizes da ação pelo pensamento científico, exato, típico das ciências naturais, na medida em que Kant estaria relegando ao pressuposto de uma regra geral, universal e necessária, o ambiente da moralidade ${ }^{3}$. O rigorismo moral kantiano obrigaria o agente a praticar uma ação, independentemente de qualquer reflexão dita sensorial ou afeita às suas vontades individuais, deslocando a busca da felicidade apenas para a composição geral, em torno da ideia da humanidade como princípio de dignidade ${ }^{4}$.

O objetivo desse trabalho é justamente compreender os potenciais de relação entre a obra de Kant e sua eventual adaptação e contribuição ao ideário advindo do campo da razão prática. Nesse sentido, a formulação de um agente inteligível, capaz de desejar e escolher um bem, e articular sua ação racionalmente em torno desse fim determinado - elementos essenciais dessa tradição - pode parecer contraditória com a noção do imperativo pela lei geral e abstrata, incondicional. Haveria na admissão do a priori como regra constitutiva da moralidade a negação da possibilidade de intermediação de vontades e intenções finalísticas ${ }^{5}$.

Além disso é importante anotar que, para muitos, Kant também negou a possibilidade de se eleger um bem superior, tendo formulado um imperativo desfeito de qualquer conteúdo

\footnotetext{
${ }^{2}$ Na sua Fundamentação, Kant diz que " [...] não se deve buscar a razão da obrigação na natureza do homem, ou nas circunstâncias do mundo, mas sim a priori unicamente em conceitos de razão pura, e que todo outro preceito baseado em princípios da mera experiência e até mesmo um preceito de certo modo universal pode certamente se chamar uma regra prática, jamais, porém, uma lei prática, na medida em que se apoia em razoes empíricas" (KANT, Immanuel. Fundamentação da Metafisica dos Costumes. Trad. Guido Antonio de Almeida. São Paulo: Barcarolla, 2009. p. 71).

${ }^{3}$ Muitos comentadores poderiam ser escolhidos para demonstrar a interpretação de que haveria na filosofia moral kantiana justamente essa invasão dos domínios do saber especulativo. Para uma compreensão mais completa desse debate, é possível mencionar além do próprio Höffe, comentadores como Loparic e Kersting. Romano Galeffi organiza algumas dessas impressões (GALEFFI, Romano. A filosofia de Immanuel Kant. Brasília: Ed. Universidade de Brasília, 1986. p. 116).

${ }^{4}$ A esse respeito, é possível citar Guyer e Sullivan: GUYER, Paul. Kant's System of Nature and Fredom: Selected Essays. New York: Clarendon Press - Oxford, 2005. p. 157; SULLIVAN, Roger J. An introduction to Kant's Ethics. Cambridge: Cambridge University Press, 1994. p. 35.

${ }^{5}$ Paul Ricoeur diz a esse respeito que "limito-me a dizer que, ao construir o conceito de a priori prático sobre o modelo do a priori teórico, Kant transferiu a investigação sobre a razão prática para uma região do saber que não é sua. Para conduzir a essa região média, que Aristóteles situava justamente entre o 'lógico' e o 'alógico', seria necessário poder associar à noção de crítica da razão prática um sentido que não fosse derivado da crítica da razão pura, por conseguinte, um sentido que apenas conviria à esfera do agir humano." (RICOEUR, Paul. Do Texto a Aç̧ão: Ensaios de Hermenêuticas. V. II. Trad. Alcino Cartaxo e Maria José Sarabando. Porto, Portugal: RÈS, 1989. p. 368).
} 
moral substancial. O pensador não aceitaria a vinculação da moralidade ao que seria um "objeto externo" à formulação da vontade. Dentro dessa crítica, a escolha de um bem apenas seria possível no acumulo histórico da vivência humana, hipótese rejeitada pelo imperativo. Dessa forma, a negação completa da sensorialidade criaria um modelo tão formal a ponto de ser vazio, desprovido da capacidade de distinguir os prazeres - negados categoricamente por Kant - de outros conteúdos externos validados moralmente como virtudes e gratificações, inviabilizando uma Ética de bens ${ }^{6}$. A ganância e a caridade, por exemplo, seriam reunidas no mesmo grande campo da sensorialidade, como se fizessem parte da mesma classe de "sentimentos morais",

Kant, em resumo, teria formulado um sistema ético que deslocaria os potenciais da agência, e obrigaria os atores sociais a aderir a uma ética formalista, e esvaziada de conteúdo moral.

Como já apontado no começo desse artigo, essa não parece a opinião mais acertada. Embora parte das críticas dirigidas ao autor possam parecer corretas, na medida em que intuíram bem alguns dos problemas normativos do sistema kantiano, a ênfase na oposição da sua arquitetura moral quando contraposta às perspectivas de uma teoria da ação e da prudência, não parece adequadamente mensurada. Em parte, acredita-se que as falhas nessa leitura podem ser explicadas por uma compreensão equivocada da natureza das regras como fundamentos da ação, e por uma parcial ignorância acerca das considerações de Kant sobre como se devem processar os julgamentos particulares.

\section{REGRAS COMO RAZÃO PARA AGIR}

Em um artigo chamado "Experts, Practitioners, and Practical Judgment", Onora O'Neill ressalta um texto pouco lembrado de Kant, em que o filósofo trata das dificuldades que os teóricos comumente enfrentam na aplicação prática de suas ideias. Para ele, esses dois campos do conhecimento - o prático e o teórico - contém um espaço fundamental a ser preenchido por princípios próprios dessa articulação ${ }^{8}$. A aplicação moral deveria compor essa

\footnotetext{
${ }^{6}$ SCHELER, Max. Ética: Nuevo ensayo de fundamentación de um personalismo ético. T. I. Trad. Hilario Rodriguez Sanz. Buenos Aires, Argentina: Revista de Occidente, 1948.. p. 68.

${ }^{7}$ Essa crítica está bem demonstrada no trabalho de José Heck (HECK, José N. Da razão prática ao Kant tardio. Porto Alegre: EDIPUCRS, 2007. p. 47.)

${ }^{8}$ Onora O'Neill comenta passagem de "On the Old Saw: That may be right in Theory but It Won't Work in Practice". (O'NEILL, Onora. Experts, Practitioners, and Practical Judgement. Journal of Moral Philosophy, vol. 4, no. 1. pp. 154-166, 2007. p. 154-157).
} 
intermediação, com base em princípios racionais que permitissem justamente que a ação prática - do sujeito que precisa decidir - se socorresse de princípios que instruíssem sua decisão ${ }^{9}$.

O’Neill ressalta a ênfase dada por Kant ao campo da prática nos assuntos de deliberação, na medida em que a preocupação moral apenas se valida no seu uso, na sua performance frente o caso concreto. Para ela, o filósofo "offers a number of considerations to show that theories of duty cannot be correct in theory yet "invalid in practice" apontando que "in the case of moral and legal duty 'the worth of practice rests entirely on its conformity with the theory underlying it" ${ }^{\prime 10}$. Mesmo na Fundamentação da Metafísica dos Costumes, ela menciona, o filósofo busca na moral concreta, cotidiana, os elementos centrais para a dedução do seu imperativo.

No artigo, O’Neill diz que em se tratando a moral de uma prática voltada a dar forma ao mundo, a sua fundamentação nessa atividade apenas pode se dar por princípios não empíricos. Afinal, não se poderia mudar o mundo concreto, o mimetizando simplesmente ${ }^{11}$. Assim, o papel dos princípios morais não seria o de suprimir os processos deliberativos dos agentes, mas antes o de informar tal ação de forma racional e adequada eticamente. É essa percepção que faz a autora afirmar que aqueles que criticam os princípios gerais no processo deliberativo, simplesmente não compreenderam o seu funcionamento ${ }^{12}$.

Essa leitura enfrenta singularmente o problema levantado para esse artigo. Como se viu, o imperativo kantiano foi criticado por ser formalista e aprisionar o agente na sua aplicação imediata e irrefletida. Se a leitura de O’Neill está correta, a operação do imperativo não seria a de deduzir uma resposta conceitual, advinda de um pressuposto geral e abstrato, como se operam as regras causais sobre os fatos da natureza. As regras morais não explicam o mundo, o constituem. Dessa forma, a lei moral kantiana deveria ser aplicada como um

\footnotetext{
${ }^{9}$ Kant diz nesse texto que "I gladly admit that no man can ever be conscious with certainty of having performed his duty quite unselfishly, for this is a matter of internal experience, and this consciousness of his state of mind would require one to have a consistently clear view of all the subsidiary notions and considerations which imagination, habit, and inclination attach to the concept of duty. We can never demand such a view, nor can the nonbeing of something (as of some hidden weighing of benefits) be an object of experience. But that man ought to perform his duty quite unselfishly, and that his desire for happiness mustbe completely divorced from his concept of duty in order to preserve its purity" (KANT, Immanuel. On the old saw: that may be right in theory but it won't work in Practice. Philadelphia: University of Pennsylvania Prees, 1974. p. 51).

${ }^{10}$ O'NEILL, Onora. Experts, Practitioners, and Practical Judgement. Journal of Moral Philosophy, vol. 4, no. 1. pp. 154-166, 2007. pp. 157-158.

${ }^{11}$ Ibid., p. 158.

${ }^{12}$ O'NEILL, Onora. Practical principles and practical judgement. Hastings Center Report, vol. 31, no. 4, pp. 15 23, 2001. p. 15 .
} 
princípio informador da ação, como um fundamento para o agente deliberante ponderar, julgar, considerar, desfeito de um perspectivismo egoísta ${ }^{13}$.

Para a compreensão do argumento completo de $\mathrm{O}^{\prime} \mathrm{Ne}$ ill é fundamental que se entenda a sua compreensão sobre como as regras funcionam. Em "Normativity and Practical Judgment", a autora aponta que as normas não definem os detalhes práticos de sua aplicação, sendo antes guias da ação. Para ela, os debates sobre como as normas devem ser aplicadas frequentemente desconsideram o caráter essencial das normas como fundamentos de conduta abstratos, considerando a sua natureza essencialmente indeterminada ${ }^{14}$. Pregando o que ela chama de uma visão "mais relaxada" das normas, o texto aponta como um erro fundamental a compreensão das normas como motor imediato da ação, como espécie de raiz causal psicológica ou motivacional. O mais apropriado seria compreender as normas como fontes de hábitos, práticas e modos de uma sociedade ${ }^{15}$, que constrói cotidianamente seus caminhos as utilizando em conjunto com as diversas fontes de normatividade, identidade e caráter.

Como elementos para informar a ação, as normas se habilitam inclusive em seu conteúdo sistêmico. Optar em aplicar uma norma e não outra, em caso de conflito entre seus conteúdos, mais do que por uma norma a falhar, derrotá-la, seria compreender a organicidade do seu papel no discernimento do julgador ${ }^{16}$, integrando os seus conteúdos normativos. Nessa interpretação, a universalidade do imperativo se converte em vínculo de condição de adoção de princípios da razão prática ${ }^{17}$. Na matriz do "seguir regras" de Wittgenstein ${ }^{18}$, mas sem cair na interpretação particularista, a função normativa não se revela na perspectiva do cumprimento de um algoritmo, mas antes na tentativa de despertar a liberdade humana sob uma perspectiva ética universal, acionando sua decisão sobre um conteúdo racional ${ }^{19}$.

\footnotetext{
${ }^{13}$ Lucien Goldmann diz que a regra moral "é também a expressão não menos radical dos fundamentos de todo verdadeiro humanismo. Pois ela nos indica o único valor supremo no qual se vêm basear todos os julgamentos. E esse valor é a humanidade na pessoa de cada homem individual. Não o indivíduo só, como nos racionalistas, nem a totalidade só em suas diferentes formas (Deus, Estado, nação, classe), como em todos os místicos românticos e intuicionistas: mas a totalidade humana, a comunidade envolvendo a humanidade inteira e sua expressão, a pessoa humana" (GOLDMANN, Lucien. Origem da Dialética: A comunidade humana e o Universo em Kant. Rio de Janeiro: Paz e Terra, 1967. p. 188).

${ }^{14}$ O’NEILL, Onora. Normativity and Practical Judgement. Journal of Moral Philosophy, vol. 4, no. 3, pgs. 393405, 2007. pp. 393-394.

${ }^{15}$ Ibid., p. 398.

${ }^{16}$ Ibid., p. 401.

${ }^{17}$ Id. Em direção à justiça e à virtude: Uma exposição construtiva do raciocínio prático. Trad. Leila Mendes. São Leopoldo: Ed. Unisinos, 1996. pp. 150-151.

${ }^{18}$ Ibid. p. 103.

${ }^{19}$ Ainda no seu "Em direção à justiça...", O'Neill diz que "o papel central que as regras têm em nossas vidas não contesta os pontos a respeito dos quais Kant e Wittgenstein concordam. As regras podem ser indispensáveis e mesmo assim indeterminadas; podem ser indeterminadas e mesmo assim guiarem a ação. Os agentes podem usar regras par dar forma à ação porque as regras não funcionam como mecanismos, e apesar do fato de que não
} 
Uma nova questão faz-se importante: deslocando o papel da regra moral para o campo da motivação do agir, habilita-se a indagação sobre qual exato tipo de papel apresenta a regra na deliberação moral. Não sendo "trilho de ação", o que é a regra?

Christine Korsgaard, no seu Creating the Kingdom of Ends, integra as visões kantianas e aristotélicas exatamente na perspectiva de reuni-los sob o campo daqueles que acreditam que existe uma razão habilitada a organizar os sentidos da ação. Embora reconheça as diferenças sobre as noções dos bens eleitos em ambos os pensadores, Korsgaard os compreende como participantes de uma tradição racionalista, capazes de atribuir valores específicos para entidades morais, a partir de uma operação intelectual provida das condições racionais $^{20}$.

Se a compreensão de que as normas são fundamentos para a ação, e não algoritmos perfeitos destinados a aplicar causalidade eficiente à ação humana, desabilita a crítica que antagoniza Kant e a tradição prudencialista de raiz aristotélica-tomista, uma nova articulação desses campos pode se dar pela percepção de que Kant compartilha com essa mesma tradição duas crenças fundamentais. Em primeiro lugar, existe um domínio inteligível, dotado dos limites constitutivos da formação da razão conforme suas versões críticas, que informa a ação humana, criando os parâmetros de aceitabilidade de uma ação; e ainda, de que a formação desses parâmetros obedece um pressuposto ético fundamental, formando critérios superiores de julgamento e organização da agência pautados na irredutibilidade da dignidade humana, na igualdade da universalidade da regra e na liberdade dos agentes. No final das contas, ambas as tradições podem afirmar que a ação é performada racionalmente, e deve obedecer metacritérios, para além da sua causa volitiva, que a conformem eticamente.

\footnotetext{
fornecem qualquer algoritmo para a ação. Ao usarmos regras, damos forma à nossa vida, formulamos juízos frequentemente juízos nuançados - tanto sobre as situações que enfrentamos quanto a respeito de linhas de ação que iremos adotar. Resumindo, as considerações sobre seguir regras não fornecem bases para se pensar que regras ou princípios, contanto que não sejam concebidos de modo enganador platônico, são impossíveis, ou dispensáveis, ou corruptores, ou mesmo dispensáveis na articulação da concordância nuançada, na discussão e articulação complexa da ação sinalizada por aqueles que são céticos a respeito de regras. As regras não são o inimigo, mas sim a matriz do juízo" (O'NEILL, Onora. Em direção à justiça e à virtude: Uma exposição construtiva do raciocínio prático. Trad. Leila Mendes. São Leopoldo: Ed. Unisinos, 1996).

${ }^{20}$ Korsgaard diz, a esse respeito, que "Aristotle and Kant agree that there are many things that are worthy of choice as ends given that one is a human being with certain physical and psychological constitution, and with certain needs and capacities for enjoyment as result. They also agree that these are conditional goods and that rationality demands more. These values of human life are only really worth pursuing if something makes a human life worth living. Both look for something that human beings can do that gives a point to being human. Both believe that practical reason at once demands a deeper justification for human existence and teaches us what will satisfy that demand. Furthermore, both are led to seek what is unconditionally good in the thought of what might be a final purpose for God, whose choices and activities are not determined by any limiting condition. Aristotle thinks that God contemplates, while Kant thinks that if God exists he must be conceived as bringing into being the Highest Good or Kingdom of Ends" (KORSGAARD, Christine M. Creating the Kingdom of Ends. Cambridge: Cambridge University Press, 1996. pp. 243-244).
} 
Esse domínio da razão, conforme ressaltado por Korsgaard, é o que diferencia a agência na perspectiva de uma relação entre homem e mundo por uma mera aplicação de sentimentos e emoções. Na introdução de "The Constitution of Agency: Essays on Practical Reason on Moral Psychology", a autora diz "What constitutes an agent? I believe that we that is, we rational beings - constitute ourselves as agents, by choosing our actions in accordance with the principles of practical reason, especially moral principles". Essa preocupação com a direção da ação humana, organiza as crenças e percepções de mundo de uma determinada comunidade, fazendo com que os agentes escolham, dentre diversos motivos e desejos, aqueles que serão habilitados como dotados da possibilidade de existência no mundo concreto ${ }^{21}$.

Para a autora, todo o processo de julgamento racional se desenha em torno de princípios - princípios de razão instrumental, prudência e morais - que ao agirem sobre os objetos podem, inclusive, constituir a percepção externa da realidade ${ }^{22}$. Isso quer dizer que a adesão do agente a um conjunto de regras modifica a sua percepção do mundo externo, afetando, racionalmente, toda a sua escala de valores e aspirações. Para ela, a existência de processos racionais que constituem o meio externo a ser percebido é justamente o que diferenciaria os homens dos animais: para esses, desejo e percepção não se poderiam diferenciar ${ }^{23}$.

Nessa perspectiva, a lei moral, organizada nessa discussão em torno da noção do imperativo, é a saída para uma nova composição da causalidade. Como bem ressaltou Kant, no mundo da natureza não há liberdade, de modo que os movimentos são imediatamente previsíveis sob a observação dos seus antecedentes causais ${ }^{24}$. Entretanto, nos assuntos humanos, é possível se pensar em uma dupla natureza ${ }^{25}$ : como seres pertencentes ao mundo fenomenológico, a humanidade é mero objeto natural, sujeito às regras da percepção geral.

\footnotetext{
${ }^{21}$ KORSGAARD, Christine M. The Constitution of Agency: essays on practical reason and moral psychology. Oxford University Press: Oxford. 2008. pp. 2-4.

${ }^{22}$ Ibid., pp. 5-7.

${ }^{23}$ Ibid., p. 3

${ }^{24}$ Importante a anotação de Ralph Walker dizendo que “[...] a liberdade de arbítrio (Willkür) que Kant defende é incompatível com o determinismo causal - a tese de que tudo o que ocorre tem alguma causa suficiente para produzi-lo. Quando as pessoas agem livremente, a vontade delas causa a ocorrência de coisas, mas nada causa tal vontade a escolher da maneira como faz. (...)o comportamento dos animais pode ser determinado mecanicamente por qualquer uma de suas mais fortes inclinações, porém, como seres racionais, podemos escolher qual de nossas inclinações seguir e se obedecemos ou não à lei moral” (WALKER, Ralph. Kant e a Lei Moral. São Paulo: Ed. UNESP, 1999. pp. 44-46).

${ }^{25}$ Também aqui muitos autores poderiam ser utilizados para explicar o papel dessa dupla natureza humana na obra kantiana. Para manter certa coerência na bibliografia usada nesse artigo, novamente Korsgaard em seu artigo em constrói um diálogo entre Kant e Parfit (KORSGAARD, Christine M. Personal identity and the unity of agency: A Kantian response to Parfit. Philosophy and Public Affairs, vol. 18, no. 2. p. 101-132, 1989).
} 
Entretanto, dotados de dignidade, os homens são livres, e com isso capazes de controlar a sua causalidade natural - na teoria kantiana representada pelos instintos naturais, as inclinações organizando uma vida não causal, capaz de deliberação e de controle total de meios de ação.

O pensamento, como ressalta Korsgaard, é o motor do movimento humano, que o faz através de princípios aplicados sobre as próprias vontades do agente. Ocorre que a liberdade, conforme mencionado acima, não permite que essa vontade seja controlada por elementos externos à mente, de modo que se opera uma auto-regulamentação autônoma da ação ${ }^{26}$. Assim, a motivação para a ação é ativada por incentivos, que como fenômenos podem até agir de forma causal na consciência humana, mas que jamais poderiam ativar automaticamente a ação. A decisão, nesses termos, é a constituição, determinada por um incentivo, de certas inclinações ${ }^{27}$ em razões de agir $^{28}$.

A regra funciona como um desses incentivos, e o imperativo é mais do que um mero princípio moral, tornando-se constitutivo, balizador da própria ação. Assim, "to be an agent is to be, at once, autonomous and efficacious - it is to have effects on the world that are determined by yourself. By following the categorical imperative we render ourselves autonomous and by following the principle of instrumental reason, we render ourselves efficacious". O imperativo ganha uma dimensão substantiva como substrato da auto determinação da agência ${ }^{29}$.

A autora apropria o problema da aplicação do imperativo sobre a decisão moral em caminho bastante semelhante ao mencionado por $\mathrm{O}^{\prime} \mathrm{Neill}$ : a arquitetura kantiana habilita as condições de inteligibilidade de decisão moral, formando deveres essenciais ao agente no que tange à racionalização da sua conduta, à universalização dos princípios invocados, e ao impedimento de tratamento instrumental do homem ${ }^{30}$. Entretanto, a deliberação, respeitadas às condições críticas dessa racionalidade, fica preservada na esfera da autonomia e da

\footnotetext{
${ }^{26}$ KORSGAARD, Christine M. The Constitution of Agency: essays on practical reason and moral psychology. Oxford University Press: Oxford. 2008. p. 11

${ }^{27}$ Korsgaard não concorda com a oposição kantiana entre ação livre e ação por inclinação. Ela diz a esse respeito que "so far as the first case is concerned, one way to understand the view that action from inclination is unfree is to suppose that the inclination operates on us as a kind of force. If the moral law has nothing to say against acting on the inclination, then I cannot help but do so. But an incentive is not a causal force that is blocked by another causal force, the moral law, and which therefore operates freely as soon as that other force gets out of the way. Is is simply a consideration that has a kind of automatic standing with a self-conscious animal prone to self-love" (KORSGAARD, Christine M. Motivation, Metaphysics, and the Value of the Self: a reply to Ginsborg, Guyer, and Schneewind. Ethics, Chicago, vol. 109, no. 1, p. 49-66, 1998. p. 56).

${ }^{28}$ Ibid., pp. 49-51.

${ }^{29}$ Id. The Constitution of Agency: essays on practical reason and moral psychology. Oxford University Press: Oxford. 2008. pp. 13-14.

${ }^{30}$ Ibid., p. 15.
} 
composição do caráter do agente ${ }^{31}$. Os imperativos kantianos, dessa forma, operam para garantir as condições da ação, quais sejam a sua eficácia e a sua autonomia ${ }^{32}$.

Decorre dessa operação, além desse teste de autonomia e eficácia da ação, a atribuição que vincula a responsabilidade do agente por seus atos. Essa atribuição ocorre em duplo sentido, do agente à ação, pelo propósito apresentado pelo sujeito que compôs a ação, e da ação ao agente, na medida em que a razão prática também constitui os seus operadores ${ }^{33}$.

Dessa forma, a compreensão do tipo de relação que as regras mantém com a ação, portanto, reorganiza a noção de Kant como um autor possivelmente integrado à noção de agência $^{34}$, diminui, em alguma medida, as divergências tradicionais entre uma Ética de bens e

\footnotetext{
${ }^{31}$ A esse respeito, também é interessante o comentário Alan H. Goldman ao dizer que "[...] this sort of objection can be answered, however, from within the Kantian framework itself. Attention to Kant's own language in many passages suggests a reply. We can think of the motivation to be rational, as well as the motivation to be moral, as a limit or accepted constraint, as a fundamental motivation only in a counterfactual sense, rather than as a force that ordinarily directly moves us to act. It need be only that person would not perform an action if it were immoral or irrational for rationality or morality to be an overriding motivation in this sense. (...) a person who satisfies this counterfactual description certainly qualifies as rational and moral in his behavior. Such a person need be neither abnormally preoccupied with rationality and morality, nor peculiarly detached from his personal projects and interpersonal relations and commitments. He need not have the constraining demands constantly in mind while engaging in everyday actions. If he has sufficiently internalized them, they will operate as constraints when required without intruding constantly into consciousness" (GOLDMAN, Alan H. Moral Knowedge. New York: Routledge, 1990. p. 108)

${ }^{32}$ Korsgaard compreende os imperativos categóricos e hipotéticos como complementares na arquitetura crítica. Na sua visão, a agência kantiana esta preocupada com a ação como movimento complexo e destinado a um bem, diferenciando-a do ato específico, singular. Dessa forma, a inteligibilidade da ação, dada pelo imperativo categórico, precisa ser composta nas suas diretrizes mais específicas, por imperativos hipotéticos. Diz a autora que "hypothetical and categorical imperatives are constitutive principles of volition and action. Unless we are guided by these principles - unless we are at least trying to conform to them - we are not willing or acting at all. The conception of action that yields this conclusion is Kant's conception: that action is determining yourself to be the cause of some end. The hypothetical imperative binds you because what you are determining yourself to be when you act is the cause of some end. The categorical imperative binds you because what you are determining to be the cause of some end is yourself. In fact, the two things are so closely bound together that they seem to be inseparable, for nothing counts as trying to realize some end that is not also trying to determine yourself to realize that end, and nothing counts as determining yourself to realize the end that is not also trying to determine your own causality" (KORSGAARD, Christine M. Self-Constitution: Agency, Identity, and Integrity. Oxford: Oxford University Press, 2009. p. 1).

${ }^{33}$ Ibid., p. 28.

${ }^{34}$ Korsgaard em um texto chamado Acting for a reason explica como justamente o tipo de relação que as normas sustentam na moralidade kantiana, aproxima o pensador da tradição aristotélica. Diz a autora que "esto significa que la visión que tiene Aristóteles de la naturaleza de la acción coincide con la de Kant. Kant cree que una acción se describe con una máxima, y que la máxima de una acción es también la máxima de la estructura de "hacer-este-acto-por-este-fi n". Kant no siempre es cuidadoso con el modo en que formula las máximas, y este hecho puede oscurecer el tema que nos ocupa, aunque en la mejor lectura de la fórmula del imperativo categórico, la máxima que se analiza incluye tanto el acto realizado como el fin por el cual se realiza dicho acto. Tiene que incluir las dos cosas, porque la cuestión planteada por la fórmula del imperativo categórico es dilucidar si podría haber una estrategia universal para perseguir este tipo de fin mediante ese tipo de médios" (Id. Actuar por uma razón. Anuario Filosófico, Pamplona, vol. 50, no. 1, p. 87-118, 2017. p. 103).
} 
de deveres ${ }^{35}$, e posta o pensador como um importante adversário do ceticismo moral ${ }^{36}$, tal qual Aristóteles. O dever moral passa a ser condição da autonomia e da liberdade do agente ${ }^{37}$.

\section{O JUÍZO E A CAPACIDADE REFLEXIVA}

O presente artigo até aqui buscou demonstrar como parte das críticas sofridas por Kant não considerou importantes elementos de como as regras funcionam, no sentido de não serem comandos imediatos da ação, mas antes uma classe de motivação. De fato, as noções de autonomia e liberdade em Kant, bem como a sua visão crítica dos limites da razão, parecem endossar a visão pela qual o imperativo desempenha um papel regulatório da agência.

Em suma, a tese aqui defendida é a de que revelando apenas elementos balizadores da ação moral, o imperativo não pode substituir o processo decisório. Naturalmente, sendo aspecto central das preocupações morais, os elementos deliberativos não poderiam ter sido negligenciados de uma boa teoria moral. E não foram: o pensador dedicou uma de suas críticas à compreensão da capacidade de julgar, especialmente ao tratar do juízo reflexivo na Crítica do Juízo ${ }^{38}$. Para completar o breve percurso desse trabalho, portanto, é importante identificar aspectos centrais da configuração dessa capacidade.

Tendo recebido atenção muito menor do que a Crítica da Razão Pura e a da Razão Prática $^{39}$, a terceira crítica é a que se destina a articular as duas primeiras. Segundo o próprio Kant, a Crítica busca compreender "se a faculdade do juízo, que na ordem de nossas faculdades de conhecimento constitui um termo médio entre o entendimento e a razão, também tem por si princípios a priori, se estes são constitutivos ou simplesmente regulativos (e, pois, não provam nenhum domínio próprio $)^{40 \%}$. O texto busca investigar se o processo decisório é coberto pelos campos da razão, e assim sendo, se é possível se identificar alguma regularidade no seu exercício.

\footnotetext{
${ }^{35}$ KORSGAARD, Christine M. The Constitution of Agency: essays on practical reason and moral psychology. Oxford: Oxford University Press, 2008. p. 19.

${ }^{36}$ A esse respeito, novamente Korsgaard em texto que analisa o ceticismo, contrapondo ao Kant: $I d$. Skepticism about Practical Reason. The Journal of Philosophy, vol. 83, no. 1, p. 5-25, Jan., 1986.

${ }^{37}$ Sobre o papel da liberdade e da autonomia em Kant, Guyer (GUYER, Paul. Kant. New York: Routledge, 2006) e Deligiorgi (DELIGIORGI, Katerina. The Scope of Autonomy: Kant and the Morality of freedom. Oxford: Oxford University Press, 2012).

${ }^{38}$ KANT, Immanuel. Crítica da Faculdade do Juizo. Trad. Valério Rohden e Antonio Marques. $3^{\text {a }}$ ed. Rio de Janeiro: Forense Universitária, 2012.

${ }^{39}$ HÖFFE, Otfried. Immanuel Kant. Trad. Christian Viktor Hamm, Valério Rohden. São Paulo: Martins Fontes, 2005. p. 293.

${ }^{40}$ KANT, op. cit., p. XVI (introdução).
} 
É importante observar que o fato do pensador atrair para o campo da razão os elementos destacados do julgar, atribuindo-lhes a tarefa de intermediar as relações entre a primeira crítica - que trata do que é possível conhecer, e, dessa forma, sobre como se pode identificar, conceituar e organizar mentalmente o mundo exterior - e a segunda - responsável pela definição dos deveres de ação, na medida da constituição dos princípios direcionadores da ação, como obra dotada de inteligibilidade de um bem desejado - é central para a composição do argumento analisado acima, na parte II do presente artigo. Isso porque, em tendo se argumentado, basicamente amparado nas ideias de O'Neill e Korsgaard, que Kant não previu um sistema de leis, regras ou princípios dedutivamente aplicáveis, no sentido causal do termo, abre-se um espaço importante a ser preenchido no pensamento do autor. Dessa forma, a edificação de um campo próprio da racionalidade dedicado justamente a unir a percepção do agente em relação ao mundo, e os princípios em relação aos quais ele deveria agir, é elemento central para a defesa da ideia de um potencial de razão prática nas ideias kantianas.

Dessa forma, a razão, que na primeira crítica apenas regulava as condições do entendimento, e que na segunda, pelo incondicionado da liberdade, ganha um papel constitutivo, agora precisa romper os ambientes dos mundos sensível e moral, fenomenológico e normativo, para articular as razões já tratadas nas demais críticas - a especulativa e a prática.

Otfried Höffe, importante estudioso de Kant, ressalta a capacidade de juízo como aquela responsável em ligar o particular ao universal. Julga, aquele que enfrentando uma situação concreta necessita apresentar o seu correspondente principiológico, seja no campo moral ou estético. É, portanto, no mundo da sensibilidade que se inicia o processo que deve buscar uma determinação universal válida, independentemente dessa mesma sensibilidade ${ }^{41}$.

Diz o comentador que:

Kant define o conceito fundamental, a faculdade de julgar, como a 'faculdade de pensar o particular enquanto contido no universal' (KU, V179). A faculdade de julgar possui duas formas. Como 'faculdade de julgar determinante', ela subsume o particular a um universal dado, a uma regra, a um princípio ou a uma lei; como faculdade de julgar reflexiva, ela deve encontrar para o particular dado o universal". Ora, Kant investiga a faculdade de julgar reflexiva pura, mediante uma

\footnotetext{
${ }^{41}$ HÖFFE, Otfried. Immanuel Kant. Trad. Christian Viktor Hamm, Valério Roden. São Paulo: Martins Fontes, 2005. p. 293-294.
} 
espontaneidade subjetiva, submete algo, que é dado a partir da sensibilidade, a uma determinação que é válida universal e independente da experiência ${ }^{42}$.

Esse juízo reflexivo, ou reflexionante, que sai do particular e busca o seu correspondente universal seria, nesses termos, justamente a capacidade adequada para o julgamento moral ${ }^{43}$. É interessante que formulando esse juízo Kant admite justamente que nesse caso, ao contrário das outras duas críticas, não é possível se formular uma razão apriorística. Chamando de lei empírica particular ${ }^{44}$, Kant praticamente forma a noção de um exercício reflexionante, que não podendo ser desassociado da empiria, da sensibilidade, precisa, ao menos, buscar condições para romper o particularismo do agente.

Assim, uma espécie de união de subjetividades, como um universal subjetivo, é o que articula a harmonia das faculdades ${ }^{45}$. Keth F. Rogerson, tratando do juízo estético, aponta essa harmonia dizendo que:

Kant holds that judgments of taste occupy a special position between mere subjectivity and outright objectivity, he wants to argue, in a way perhaps unique to the history of philosophy, that aesthetic judgments are 'subjectively universal'. They are subjective since they are based on our feeling of pleasure. However, according to Kant, aesthetic judgments are more than this ${ }^{46}$.

\footnotetext{
${ }^{42}$ HÖFFE, Otfried. Immanuel Kant. Trad. Christian Viktor Hamm, Valério Roden. São Paulo: Martins Fontes, 2005., p. 293-294.

${ }^{43}$ Douglas Burham trata do chamado juízo reflexivo, dizendo que "[...] this principle of purposiveness presupposes that the empirical concepts revealed in particular objects of judgement will always belong to a system of such concepts and of concepts laws, just as if they were already the product of an understanding (V: 180). Kant argues that every judgment, in order to be possible, must act (subjectively) within the assumption that its particular conceptual content belongs within a system (ultimately an all-inclusive system) of wider concepts and of laws governing concepts. Objectively, he describes this as the assumption that all appearances will be amenable to our judgements" (BURNHAM, Douglas. Kant's Philosophies of Judgement. Edinburgh: Edinburgh University Press, 2004. p. 151)

${ }^{44}$ Kant diz "[...] ora, este princípio não pode ser senão este: como as leis universais tem o seu fundamento no nosso entendimento, que as prescreve à natureza (ainda que somente segundo o conceito universal dela como natureza), tem as leis empíricas particulares, a respeito daquilo que nelas é deixado indeterminado por aquelas leis, de ser consideradas segundo uma tal unidade, como se igualmente um entendimento (que não o nosso) as tivesse dado em favor da nossa faculdade de conhecimento, para tornar possível um sistema de experiência segundo leis da natureza particulares" (KANT, Immanuel. Crítica da Faculdade do Juizo. Trad. Valério Rohden e Antonio Marques. $3^{a}$ ed. Rio de Janeiro: Forense Universitária, 2012. p. 12).

${ }^{45} \mathrm{Höffe}$, falando do gosto estético, faz um levantamento dessa universalidade subjetiva dizendo que "[...] visto que o a priori estético não coincide com os princípios do conhecimento e da ação, as questões estéticas não se deixam resolver adequadamente aos fenômenos, nem por argumentação e demonstração, nem por engajamento. Apesar disso, não são a preferência individual nem o arbítrio subjetivo que decidem. Os juízos estéticos, nisso Kant insiste, contém uma notável tensão. Eles não são suscetíveis de prova e, contudo, reclamam ser universalmente compreensíveis e vinculantes para qualquer um”. Depois completa: “à diferença de asserções científicas e morais, Kant não atribui aos juízos estéticos uma universalidade objetiva mas uma universalidade subjetiva. No sentimento subjetivo do eu da experiência estética, está contido, ao mesmo tempo, um sentimento universal de mundo e de vida e a problemática do estético aguça-se na questão de como a subjetividade pode vincular-se com a pretensão de universalidade e necessidade" (HÖFFE, op. cit., p. 299).

${ }^{46}$ ROGERSON, Kenneth F. The Problem of Free Harmony in Kant's Aesthetics. New York: State University of New York Press, 2008. p. 1.
} 
A união desses particulares concretos em um sentido unitário se dá por uma noção de fim $^{47}$, partindo-se das subjetividades individuais para que se possa encontrar um sentido comum, compartilhado nessas subjetividades ${ }^{48}$. Como no gosto, o juízo apenas faz sentido se é comunicável e parte de um ideário que não sendo objetivo - pois trata de um exercício do particular ao universal - necessita ser inteligível comunitariamente ${ }^{49}$.

Ao fazer isso, Kant está justamente enfrentando as necessidades próprias do campo da deliberação estética e moral, e definitivamente pacificando o seu entendimento sobre a impossibilidade de realizar tal procedimento em viés especulativo. A hipótese pela qual o imperativo deveria ser auto aplicável, como regra dedutiva necessária, desconsideraria, portanto, a colocação do pensador de que o julgamento - que dá uma resposta conceitual (universal) a um problema concreto enfrentado pelo agente (particular) - para ser compreendida como correta deveria necessariamente desconsiderar a capacidade de julgamento como ferramenta dotada de razão própria, e mais do que isso, amparada em alguma sensibilidade, ainda que uma sensibilidade comum, compartilhada.

Interessante que na "Fundamentação da Metafísica dos Costumes", como já ressaltado, Kant sai da moral particular, utilizando-se de exemplos cotidianos, para buscar o supremo fundamento ético. Essa transição é validada por uma noção de finalidade, da própria existência digna do homem, que permite a dedução do imperativo como a lei universal ${ }^{50}$. Nessa perspectiva, parece bastante razoável entender que tal como na própria formulação da lei moral, Kant compreenda o papel do juízo reflexionante como aglutinador da formação de

\footnotetext{
${ }^{47}$ KANT, Immanuel. Crítica da Faculdade do Juizo. Trad. Valério Rohden e Antonio Marques. $3^{\mathrm{a}}$ ed. Rio de Janeiro: Forense Universitária, 2012. p. 12-13.

${ }^{48}$ Gilles Deleuze aponta que a articulação dessa capacidade se dá justamente por um potencial teleológico. Diz ele que "Se considerarmos os interesses da razão que correspondem às duas formas do juízo reflexivo reencontramos o tema de uma 'reparação' mas num outro sentido. A estética manifesta um acordo livre das faculdades, que se liga de uma certa maneira a um interesse especial pelo belo; ora, este interesse predestina-nos a ser moral, logo, prepara o advento da lei moral ou a supremacia do interesse prático puro. A teleologia, por seu lado, manifesta um acordo livre das faculdades, desta vez, no próprio interesse especulativo: 'sob' a relação das faculdades tal como ela é determinada pelo entendimento legislador, descobrimos uma livre harmonia de todas as faculdades entre si, donde o conhecimento extrai uma via própria (vimos que o juízo determinante, no conhecimento mesmo, implicava um fundo vivo que apenas se revela à «reflexão»). Deve então pensar-se que o juízo reflexivo em geral toma possível a passagem da faculdade de conhecer à faculdade de desejar, do interesse especulativo ao interesse prático, e prepara a subordinação do primeiro ao segundo, ao mesmo tempo que a finalidade toma possível a passagem da natureza à liberdade ou prepara a realização da liberdade na natureza" (DELEUZE, Gilles. A Filosofia Crítica de Kant. Lisboa: Edições 70, 1963. p. 72).

${ }^{49}$ A esse respeito, Béatrice Longuenesse (LONGUENESSE, Béatrice. Kant and the Capacity of Judge: Sensibility and Discursivity in the transcendental analytic of The Critic of Pure Reason. Princeton, NJ: Princeton University Press, 2000.).

${ }^{50}$ DELIGIORGI, Katerina. The Scope of Autonomy: Kant and the Morality of freedom. Oxford: Oxford University Press, 2012. p. 51-52.
} 
um juízo moral completo, possível de aplicação de uma ação inteligível, e dotada de sentido e propósito $^{51}$.

É importante anotar que a aparição da ideia de um juízo reflexionante não resolve muitos dos problemas relativos à aplicação das regras, e nem mesmo ao julgamento prático. ${ }^{52}$ Entretanto, consolida um entendimento importante sobre o "seguir regras", sobretudo no pensamento de matriz kantiana: a existência de uma capacidade específica, dotada da possibilidade de produzir um juízo sobre o particular indutivamente, é passo importante em uma compreensão mais harmônica entre a moralidade kantiana e as perspectivas envoltas em uma noção de razão prática.

\section{CONCLUSÃO}

Os caminhos abertos pelos comentadores poderiam ter sido mais bem desenvolvidos nesse trabalho, na perspectiva de uma compreensão mais apropriada do sentido de aplicação do imperativo, como regra a ser seguida, e sobretudo na tentativa de compreender os potenciais gerados por uma visão integrada da Crítica do Juízo em direção às considerações morais kantianas. O pouco espaço desse artigo não permite uma avaliação mais criteriosa desses elementos. Entretanto, é importante pacificar as conclusões possíveis a partir das considerações trazidas, e de que forma entende-se que uma boa aceitação desses argumentos inviabilizaria uma leitura de Kant como um autor contrário às noções de razão prática.

Em primeiro lugar, esse artigo tentou enfrentar o argumento de que Kant previu um imperativo formalista e rígido, que aplicado na vida moral geraria uma condição de heterônoma no agente, impossibilitado de decidir a seu respeito. Na verdade, interpretou-se o corolário da regra apriorística, afastada da sensibilidade, como uma prisão deliberativa, em que o ator moral simplesmente deveria deduzir as respostas para os diversos problemas éticos enfrentados a partir de uma fórmula bem desenhada pelo imperativo, na medida em que se ele decidisse concretamente incorreria em uma visão necessariamente particular.

Admitir essa interpretação exigiria, em primeiro lugar, desconsiderar tudo o que Kant disse sobre a dupla natureza humana, a capacidade "divina" advinda da sua liberdade como ser não causal, e o papel da autonomia na formação do seu caráter moral. É justamente por ser

\footnotetext{
${ }^{51}$ Samuel Fleischacker defende a existência de uma teoria da ação na Terceira Crítica (FLEISCHACKER, Samuel. A third Concept of Liberty: Judgment and Freedom in Kant and Adam Smith. Princeton: Princeton University Press, 1999).

${ }^{52}$ O'NEILL, Onora. Normativity and Practical Judgement. Journal of Moral Philosophy, vol. 4, no. 3, pgs. 393405, 2007. p. 402.
} 
livre, e poder decidir o que quiser, que o homem deve ter um critério racional, não afetado pela vida concreta e pelos valores mundanos, informando principiologicamente suas decisões. O imperativo é uma condição de agir racionalmente. Além de não ser contrário a uma razão prática, é possível dizer que o imperativo é justamente um instrumento dessa noção.

É por isso que esse artigo se utilizou de intérpretes kantianos para defender que, em parte, a crítica ao rigorismo e formalismo moral do pensador é advinda de uma compreensão equivocada do que é "seguir regras", e de como funcionam as regras como motores da ação. Nesse sentido, a crítica do formalismo moral, ou seja, de que o imperativo não teria conteúdo ético, parece necessariamente revelar o apego de Kant pelo tema da agência: o imperativo não pode impor um conteúdo material forte, porque, em algum sentido, isso será dado pelo agente na deliberação concreta. O que a regra moral pode fazer é estabelecer condições de inteligibilidade da ação - obrigando a agência a ser construída com base em uma lei geral, e não particular, de modo a poder ser compartilhada linguisticamente entre todos os participantes dessa comunidade moral - e impor um mínimo ético a ser observado por qualquer agente em concreto - a impossibilidade de se tratar o homem como fim, e diferenciá-lo em sua liberdade e dignidade pela adoção de regras particulares.

Por fim, essas considerações são completadas pela demonstração, ainda que bastante rápida, da existência de uma preocupação autônoma do pensador com o tema do julgamento. $\mathrm{O}$ cuidado de Kant com o assunto é tamanho que ele admite que em todo o seu edifício racional, construído para buscar elementos apriorístico como balizadores da atividade, o campo do julgamento é exatamente a exceção. Nessa quadra, o máximo possível, no sentido de afastá-lo da sensibilidade individual, é projetá-lo para uma sensibilidade ampliada, uma espécie de sensibilidade universal.

É importante reparar, nesse sentido, que a admissão de Kant de que a tarefa de julgar é essencialmente subjetiva - ainda que seja essa subjetividade indisponível ao sujeito moral individualmente - é, antes de tudo, um prestígio fundamental à noção de agência. Dando os critérios racionais da ação, e da inteligibilidade dos bens buscados, a segunda crítica não se aplica sozinha no mundo. Ela precisa da intermediação subjetiva do julgamento, através de uma noção de subjetividade ampliada.

Dessa forma, acredita-se que o fato de que o imperativo não foi engendrado para ser auto aplicável automaticamente, como motor necessário, rearticula uma possível compreensão de Kant como um pensador desligado da tradição da razão prática. Demonstrando como as regras realmente funcionam, e a construção de uma capacidade de julgamento em Kant, esse 
trabalho pretende ter contribuído para demonstrar uma aplicação do imperativo como princípio constitutivo e balizador da ação.

\section{REFERÊNCIAS}

BURNHAM, Douglas. Kant's Philosophies of Judgement. Edinburgh: Edinburgh University Press, 2004.

DELEUZE, Gilles. A Filosofia Crítica de Kant. Lisboa: Edições 70, 1963.

DELIGIORGI, Katerina. The Scope of Autonomy: Kant and the Morality of freedom. Oxford: Oxford University Press, 2012.

FLEISCHACKER, Samuel. A third Concept of Liberty: Judgment and Freedom in Kant and Adam Smith. Princeton: Princeton University Press, 1999.

GALEFFI, Romano. A filosofia de Immanuel Kant. Brasília: Universidade de Brasília, 1986.

GOLDMAN, Alan H. Moral Knowedge. New York: Routledge, 1990.

GOLDMANN, Lucien. Origem da Dialética: A comunidade humana e o Universo em Kant. Rio de Janeiro: Paz e Terra, 1967.

GUYER, Paul. Kant. New York: Routledge, 2006.

GUYER, Paul. Kant's System of Nature and Fredom: Selected Essays. New York: Clarendon Press - Oxford, 2005.

HECK, José N. Da razão prática ao Kant tardio. Porto Alegre: EDIPUCRS, 2007.

HÖFFE, Otfried. Immanuel Kant. Trad. Christian Viktor Hamm, Valério Roden. São Paulo: Martins Fontes, 2005.

KANT, Immanuel. Crítica da Faculdade do Juízo. Trad. Valério Rohden e Antonio Marques. 3. ed. Rio de Janeiro: Forense Universitária, 2012.

KANT, Immanuel. Crítica da Razão prática. Trad. Afonso Bertagnoli. Rio de Janeiro: Nova Fronteira, 2013.

KANT, Immanuel. Fundamentação da Metafísica dos Costumes. Trad. Guido Antonio de Almeida. São Paulo: Barcarolla, 2009.

KANT, Immanuel. On the old saw: that may be right in theory but it won't work in Practice. Philadelphia: University of Pennsylvania Prees, 1974. 
KORSGAARD, Christine M. Actuar por uma razón. Anuario Filosófico, Pamplona, vol. 50, no. 1, p. 87-118, 2017. p. 103

KORSGAARD, Christine M. Creating the Kingdom of Ends. Cambridge: Cambridge University Press, 1996.

KORSGAARD, Christine M. Motivation, Metaphysics, and the Value of the Self: a reply to Ginsborg, Guyer, and Schneewind. Ethics, Chicago, vol. 109, no. 1, p. 49-66, 1998.

KORSGAARD, Christine M. Personal identity and the unity of agency: A Kantian response to Parfit. Philosophy and Public Affairs, vol. 18, no. 2. p. 101-132, 1989.

KORSGAARD, Christine M. Self-Constitution: Agency, Identity, and Integrity. Oxford: Oxford University Press, 2009.

KORSGAARD, Christine M. Skepticism about Practical Reason. The Journal of Philosophy, vol. 83, no. 1, p. 5-25, Jan., 1986.

KORSGAARD, Christine M. The Constitution of Agency: essays on practical reason and moral psychology. Oxford: Oxford University Press, 2008.

LONGUENESSE, Béatrice. Kant and the Capacity of Judge: Sensibility and Discursivity in the transcendental analytic of The Critic of Pure Reason. Princeton, NJ: Princeton University Press, 2000.

O`NEILL, Onora. Experts, Practitioners, and Practical Judgement. Journal of Moral Philosophy, vol. 4, no. 1. pp. 154-166, 2007.

O`NEILL, Onora. Practical principles and practical judgement. Hastings Center Report, vol. 31, no. 4, pp. 15-23, 2001.

O`NEILL, Onora. Normativity and Practical Judgement. Journal of Moral Philosophy, vol. 4, no. 3, pgs. 393-405, 2007.

O’NEILL, Onora. Em direção à justiça e à virtude: Uma exposição construtiva do raciocínio prático. São Leopoldo: Editora Unisinos, 2005.

RICOEUR, Paul. Do Texto a Acção: Ensaios de Hermenêuticas. V. II. Trad. Alcino Cartaxo e Maria José Sarabando. Porto, Portugal: RÈS, 1989.

ROGERSON, Kenneth F. The Problem of Free Harmony in Kant's Aesthetics. New York: State University of New York Press, 2008.

SCHELER, Max. Ética: Nuevo ensayo de fundamentación de um personalismo ético. T. I. Trad. Hilario Rodriguez Sanz. Buenos Aires, Argentina: Revista de Occidente, 1948.

SUlliVAN, Roger J. An introduction to Kant's Ethics. Cambridge: Cambridge University Press, 1994. 
WALKER, Ralph. Kant e a Lei Moral. São Paulo: Ed. UNESP, 1999.

\section{DADOS DA PUBLICAÇÃO}

Categoria: artigo submetido ao double-blind review.

Recebido em: 09/07/2018.

Aceito em: 14/10/2019. 
PEREIRA, Paulo Henrique Rodrigues. Normas como princípios de ação e capacidade reflexiva: fundamentos para a compreensão da Razão Prática kantiana. Revista da Faculdade de Direito da UFRGS. Porto Alegre, n. 